\title{
Liquid Drying by Solid Desiccant Materials: Experimental Study and Design Method
}

\author{
F. Augier ${ }^{1}$, C. Boyer ${ }^{1}$ and M. Vassieu ${ }^{2}$ \\ 1 Institut français du pétrole, IFP, BP 3, 69390 Vernaison - France \\ 2 Newton's, ZA Le Camp, 850 ch. du Mitan, 84300 Cavaillon - France \\ (http://www.newton-s.com) \\ e-mail: frederic.augier@ifp.fr - christophe.boyer@ifp.fr - mvassieu@newton-s.com
}

\begin{abstract}
Résumé - Séchage de liquides par des solides déliquescents : étude expérimentale et méthode de dimensionnement — L'utilisation de solides déliquescents consommables pour le séchage de liquides organiques est très courante dans les procédés de raffinage ou de l'industrie chimique, notamment lorsque les teneurs en eau à éliminer sont faibles $(<1000 \mathrm{ppm})$. Malgré leur utilisation fréquente, la cinétique de séchage de liquides par ces solides déliquescents n'est pas bien connue, et le dimensionnement des procédés de séchage utilisant ces matériaux est toujours problématique. Dans cette étude, est analysée la cinétique de séchage de deux liquides organiques, le di-propylène glycol et le toluène, par des solides déliquescents classiques de type-1. Des expérimentations sont réalisées à trois échelles différentes, en utilisant différentes mises en œuvre opératoires : un réacteur batch agité, un pilote de petite taille et un pilote semi-industriel. Les résultats obtenus à ces différentes échelles mettent en évidence une forte limitation au transfert de matière. Sur la base de ces résultats, un modèle simple est développé pour le dimensionnement de colonnes de séchage à partir de données obtenues sur le petit pilote. Le modèle est capable de prédire l'évolution des performances de séchage avec le temps et reproduit avec une bonne précision des essais réalisés sur le pilote semi-industriel.
\end{abstract}

Abstract - Liquid Drying by Solid Desiccant Materials: Experimental Study and Design Method The use of consumable solid desiccant materials for organic liquid dehydration is very current in refinery or chemistry processes, especially when the water concentration is very low $(<1000$ ppm). In spite of its common use, the kinetics of liquid drying by solid desiccants is not well known, and scale-up of industrial drying processes using such materials is always problematic. In this study, the kinetics of drying of two organic liquids, dipropylene-glycol (DPG) and toluene, with some classical "type-1" desiccant materials is analysed. The experiments were done on three different scales, by using different appropriate apparatus: a laboratory stirred reactor, a small pilot and a semi-industrial pilot. The results show that dehydration kinetics is driven by a strong mass transfer limitation. Based on these results, a simple model is developed in order to design industrial drying columns from pilot data. This model is able to predict the time evolution of the water content at the outlet of the column, and the resulting simulations are in good agreement with experiments. 


\section{NOTATION}

A Specific area of the desiccant $\left(\mathrm{m}^{2} / \mathrm{m}^{3}\right.$ of column $)$

$C_{0} \quad$ Water concentration at the inlet of the column (\%)

$C_{S} \quad$ Water concentration at the outlet of the column (\%)

$d_{h} \quad$ Hydraulic diameter of solids (m)

$d_{c} \quad$ Column diameter $(\mathrm{m})$

$D \quad$ Diffusivity of water in a solvent $\left(\mathrm{m}^{2} / \mathrm{s}\right)$

$D_{a x} \quad$ Axial dispersion in the column $\left(\mathrm{m}^{2} / \mathrm{s}\right)$

Eff Dehydration efficiency (-)

$K \quad$ Liquid-solid mass transfer coefficient (m/s)

$k_{L}, k_{d} \quad$ External and diffusional mass transfer coefficients $(\mathrm{m} / \mathrm{s})$

$L \quad$ Height of solid in the column (m)

$M \quad$ Mass of solid in the column $(\mathrm{kg})$

$M_{0} \quad M$ at $t=0(\mathrm{~kg})$

$S \quad$ Section of the column $\left(\mathrm{m}^{2}\right)$

$t \quad$ Time (s)

$Q \quad$ Liquid flow rate $\left(\mathrm{m}^{3} / \mathrm{s}\right)$

$U_{s} \quad$ Superficial velocity $(\mathrm{m} / \mathrm{s})$

$x \quad$ Distance from the inlet of the column (m)

$X \quad$ Water/soda or water/potash ratio in the brine $(\mathrm{kg} / \mathrm{kg})$

$\rho_{D} \quad$ Density of solid $\left(\mathrm{kg} / \mathrm{m}^{3}\right)$

$\rho_{L} \quad$ Density of liquid $\left(\mathrm{kg} / \mathrm{m}^{3}\right)$

$\varepsilon \quad$ Extra-granular porosity (-)

$\rho \quad$ Density of solvent $\left(\mathrm{kg} / \mathrm{m}^{3}\right)$

$\mu \quad$ Viscosity of solvent (pa.s)

Pe Peclet number: $U_{s} L / D_{a x}$

Sh Sherwood number: $K . d h / D$

Re Reynolds number: $\rho . U_{s} \cdot d h /(\varepsilon . \mu)$

Sc Schmidt number: $\mu /(\rho . D)$

\section{INTRODUCTION}

Desiccants are dehydration agents used to remove water from liquid, or more frequently from gaseous media. They can be found in the liquid or solid phase, and this paper only deals with solid desiccants. Different types of desiccants can be found; some of them can be regenerated, and others are simply consumed during the dehydration process. This last type of solid generally allows a deeper dehydration. Classically, desiccants or drying agents are classified as follows. Type 1: chemical reaction and formation of a hydrate; type 2: physical adsorption with constant relative humidity (formation of a saturated aqueous phase); type 3: physical adsorption with variable relative humidity (formation of a diluted aqueous phase) and type 4: physical adsorption (no aqueous phase formed). This paper deals with the use of consumable solid desiccants classified as type 1 for water removal in organic liquid phases as solvents or hydrocarbons, because of their common use in the petroleum industry. The paper focuses on the removal of the solvent-soluble part of the water: the case of non-miscible microemulsions was not studied. Although solid desiccants are frequently used in the field of gas treatment, the literature is poor on this subject compared with the literature dealing with liquid desiccants. No specific study about dehydration of liquids by solid desiccants has been found. Some reviews of classical desiccants are available in the literature $[1,2]$, but efficiencies are always reported in terms of residual water contents in the air, at equilibrium with desiccants. No details about dehydration mechanisms or kinetics are given. A current application of solid desiccants is the dehydration of fuels or gas oils in the refineries by rock salt or calcium chloride $[3,4]$. Dehydration of fuel is important because water phase demixion (called haze) is prohibited.

The outline of this study is the development of design procedures for hydrocarbon dryers. It focuses mainly on the measurement and analysis of dehydration kinetics, essential for industrial contactor modelling and scale-up.

Industrial dryers using solid desiccants for solvent cleaning or fuel dewatering are generally fixed-bed columns filled with solid granular pearls, pellets or flakes. The liquid phase flows through the fixed bed in an upward or downward flow direction [5]. The upward flow direction is preferred when the dehydration process generates the production of a brine phase. In this case, the brine phase settles at the bottom of the columns and does not interact with the dehydration in the upper part of the column. The brine can also enhance the solvent dehydration by further extraction in counter-current flow, as will be seen below. In this case, it is necessary to operate at low velocity in order to avoid bed fluidisation and the overflooding of the brine. By operating in downward flow conditions, the liquid flow rate can be increased, but strong dehydrations will be more difficult due to the presence of the brine over the whole column, which can sometimes generate a thermodynamic limit to the treatment (as observed below during batch experiments).

Three kinds of classical solid desiccants are used in this study: Calcium Chloride $\left(\mathrm{CaCl}_{2}\right)$, Sodium Hydroxide or Soda $(\mathrm{NaOH})$ and Potassium Hydroxide or Potash $(\mathrm{KOH})$. The latter two solids are theoretically more efficient for dehydration but more difficult to handle because of their strong causticity. Calcium chloride has been used for natural gas treatment since the beginning of the 20th century [2]. The solids used in this study are mainly moulded pieces with a specific form of cushion. These solids are those commercialised by the company Newton's. Some tests with flakes and pearls were also done in the study. Figure 1 shows different kinds of solid shape available (flakes, and $9 \mathrm{~g}$ and $28 \mathrm{~g}$ moulded pieces, from left to right). The scale is in $\mathrm{cm}$.

The interest in the moulded pieces used here is a higher specific contact area between solid and liquid compared with pearls of the same volume: the gain of specific area is around $20 \%$, with a similar pressure drop. When very high specific areas are needed (i.e. for deep dehydrations), other shapes and sizes can be used, such as small pellets or flakes, but in these cases, pressure drop through the bed can be much higher, and during operation the formation 


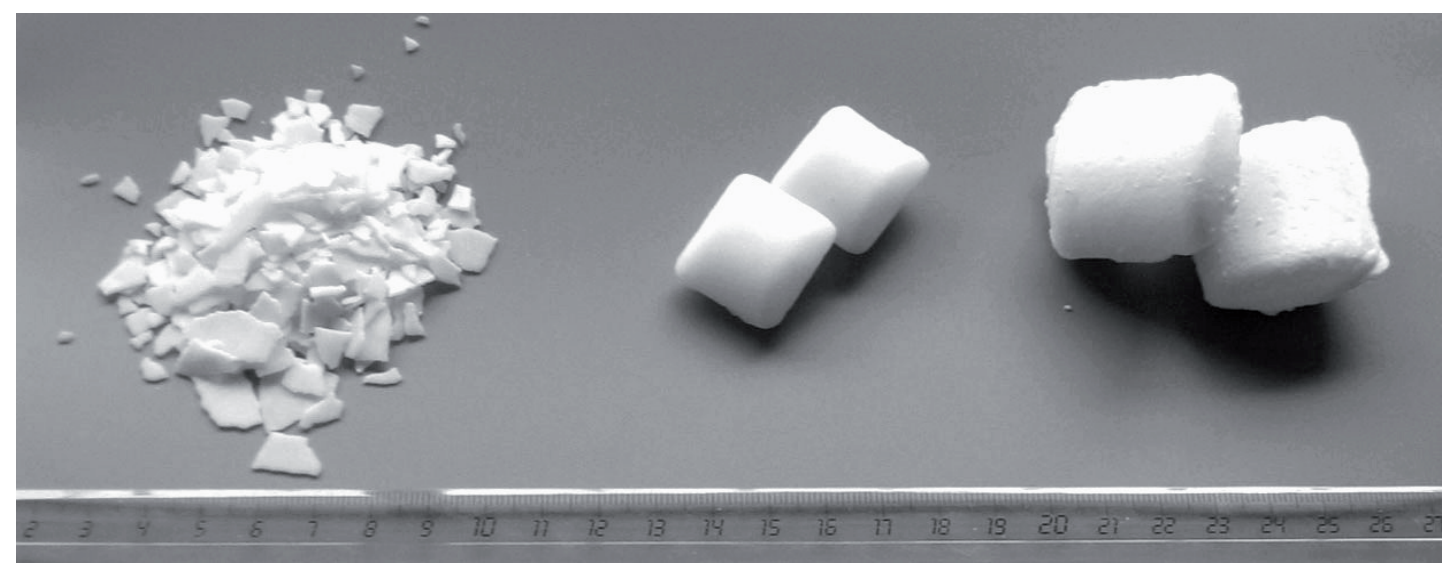

Figure 1

Different types of solid commercialised by the company Newton's.

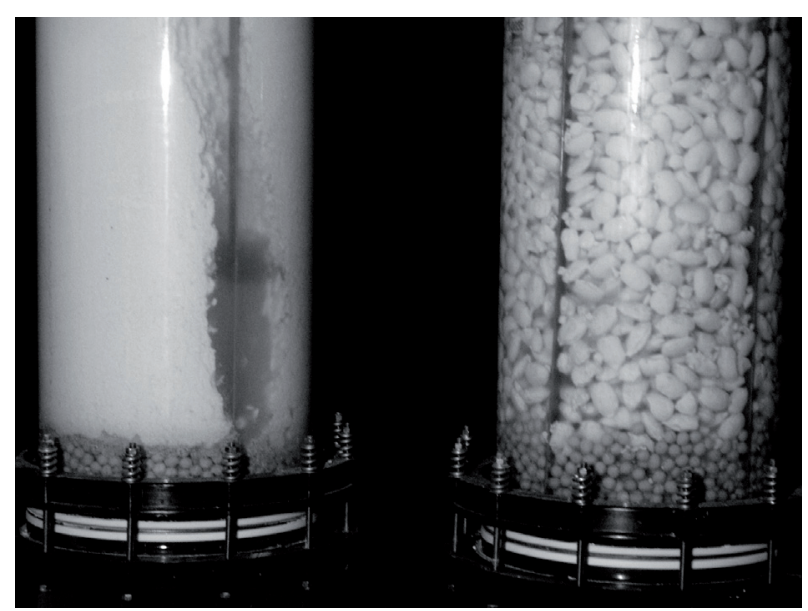

Figure 2

Flakes' (left) and moulded pieces' (right) bed consumption.
The study follows three steps:

- batch experiments for the analysis of dehydration limitations and mechanisms,

- small pilot experiments for mass transfer measurements,

- big pilot experiments for desiccant consumption measurements on a large scale and long-term tests.

Tests were done with two different solvents: toluene, with a small water content ( $\approx 500 \mathrm{ppm}$ ), and dipropylene glycol (DPG) with a higher water content $(\approx 1.5 \%)$. These solvents were chosen for different reasons. They have very different physical properties, especially viscosity. This induces important differences in Schmidt numbers between both systems. Toluene is representative of gasoline or light diesel fuel, so its dehydration is interesting concerning oil refinery processes. DPG is more representative of solvent or chemical products that can be found in the pharmaceutical or cosmetic industries.

\section{BATCH EXPERIMENTS}

\subsection{Dynamic Dehydration}

Batch experiments were performed with DPG containing $1.8 \%$ of water $(\mathrm{w} / \mathrm{w})$. A $28 \mathrm{~g}$ moulded piece of caustic soda, caustic potash or calcium chloride is introduced into a vessel containing $600 \mathrm{ml}$ of DPG, and magnetically agitated at $40 \mathrm{rpm}$, at $20^{\circ} \mathrm{C}$. Water concentration in the solvent is measured over time by a Karl Fischer method, and the results are reported in Figure 3 (logarithmic scale). Concentrations measured with potash and soda are close and follow a decreasing exponential curve. This behaviour is typical of an external mass transfer limitation. The water concentrations measured with the calcium chloride are different and seem to reach a not-null minimum level. To characterise the mass transfer observed with caustic desiccants, it 


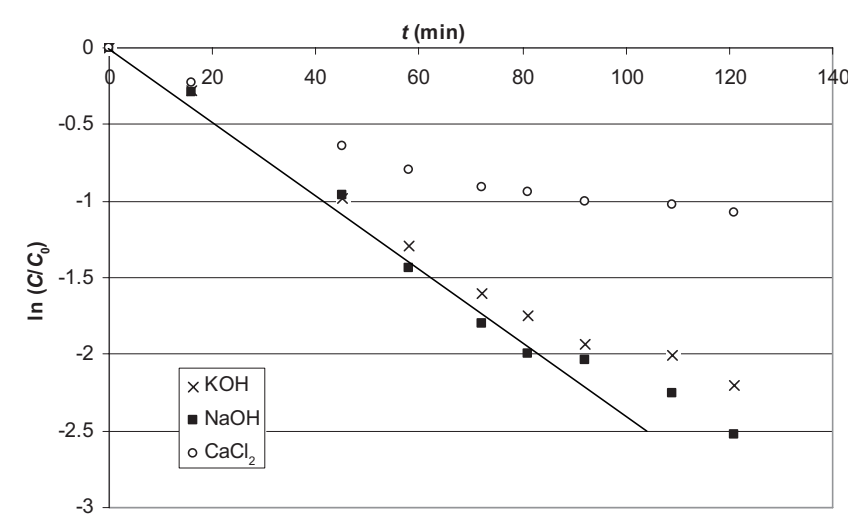

Figure 3

Water concentration in DPG in the presence of an excess of desiccant solid.

is necessary to perform experiments in hydrodynamic conditions close to industrial ones, because of the sensitivity of external mass transfer to hydrodynamic local conditions (local velocity, static and dynamic zones). These tests will be described in Paragraph 3. With both caustic desiccants, the apparition of a brine phase is observed. This phase is not soluble in DPG and contains around $50 \%$ of water and $50 \%$ of potash or soda. The brine is a mixture of calcium chloride hexahydrates and water, and its presence shows that sodium and potassium hydroxides can also be considered as type- 2 drying agents. Brine generation is not seen with the calcium chloride. The water is adsorbed in the salt without dissolving it.

\subsection{Dehydration Limit}

A novel experiment is done in order to measure the maximum limit of dehydration on batch mode without brine phase removal. Using three closed vessels, agitated as before, and containing $200 \mathrm{ml}$ of solvent, different quantities of solid are progressively introduced into the vessels. At each introduction the vessel is stirred for $4 \mathrm{~h}$ and after decantation the water concentration in the solvent is measured. Both DPG and toluene are tested as the liquid phase to dehydrate. Initial water concentrations in solvents are $1.5 \%$ in DPG and 300 to $500 \mathrm{ppm}$ in toluene. The results are reported in Figure 4.

These experiments show that:

- In the case of DPG, an equilibrium is reached and there is no effect when introducing more than $30 \mathrm{~g}$ of solid into the vessel. Final equilibriums are different between caustic potash and soda. These equilibriums are controlled by the presence of the brine phase.

- In the case of toluene as solvent, potash and soda are very similar and do not exhibit any limit in the dehydration

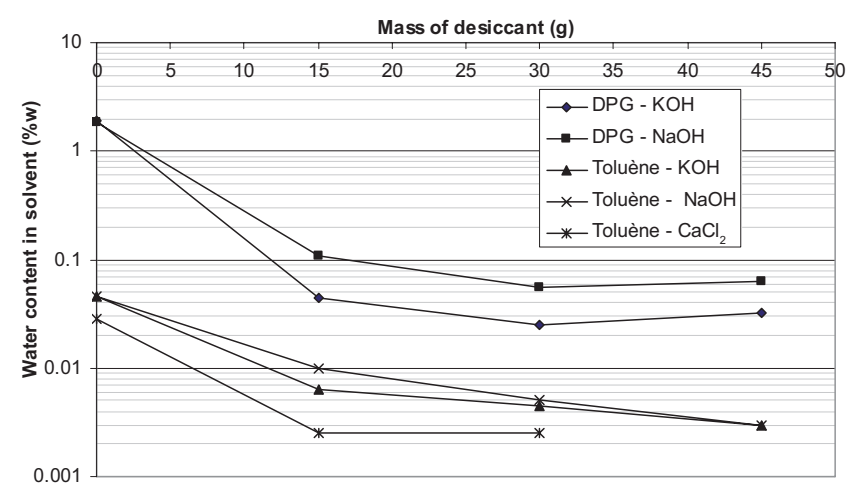

Figure 4

Water concentrations in solvents at equilibrium when in contact with different quantities of desiccant.

process. This is due to the small content of water in the solvent, which is not sufficient to produce any brine phase. In this case, the concentration of water can be strongly decreased by the desiccant. It also proves the limitation of the dehydration due to the presence of the brine phase.

- In the case of calcium chloride as desiccant, an equilibrium is reached after the introduction of $15 \mathrm{~g}$ of desiccant, even if no brine phase is observed. This shows that the water diffuses inside calcium chloride without dissolving it, and a saturation phenomenon occurs inside the desiccant.

\subsection{Impact of the Brine Phase on Dehydration}

In order to provide a better understanding of the impact of the brine phase, some experiments were done by putting a humid solvent in contact with a brine phase saturated with potash or soda ( $\approx 50 \%$ water initially). A volume of $400 \mathrm{ml}$ of solvent (DPG or toluene) is introduced into an agitated vessel at $20^{\circ} \mathrm{C}$, with different volumes of soda or potash brine. After a contact time of $4 \mathrm{~h}$, water concentrations are measured in the solvent phase, and reported in Figure 5. For both solvents, the brine phase partially dehydrates the solvent, and an equilibrium can be observed after introduction of around $50 \mathrm{ml}$ of brine into the vessel. This confirms that the presence of a brine phase generates a thermodynamic equilibrium between water concentrations in aqueous and organic phases. Concerning the DPG, the minimum water concentration is higher with the calcium chloride than with caustic desiccants. This experiment shows that the brine can be potentially used to perform a part of the dehydration. This point should be taken into account in the design of dryers for high water content in the solvent, because in this case the quantity of brine produced is significant, as is its dehydration potential. 

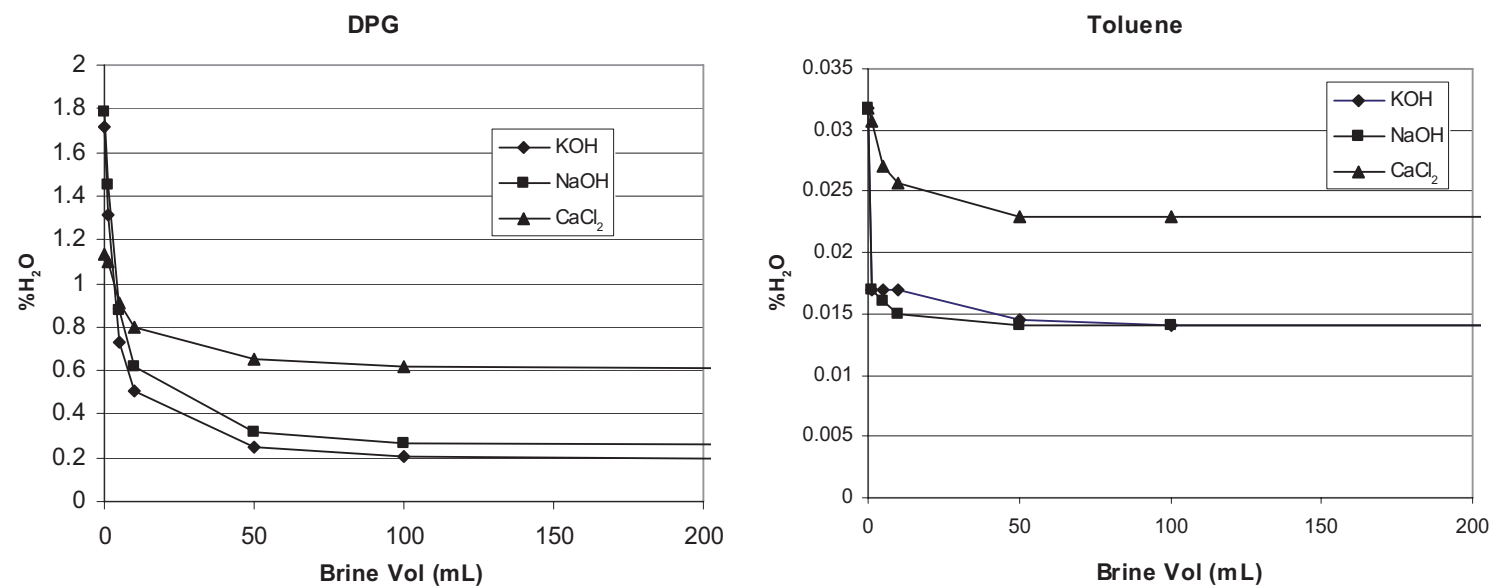

Figure 5

Water concentrations in solvents at equilibrium when in contact with different quantities of brine (left: DPG, right: toluene).

Some conclusions about these preliminary experiments:

- Soda and potash have very similar behaviour, except at very low concentrations of water.

Calcium chloride has a different behaviour, and a dehydration capacity smaller than caustic desiccants.

- Concerning caustic desiccants, and when the concentration of water in the solvent is far from its equilibrium value with the desiccant, dehydration is limited by the external mass transfer.

The presence of a brine phase can have a strong impact on the dehydration:

- For solvents with high water concentrations (after dehydration), the brine can help with the extraction, so it is important to maximise the interfacial area between the brine and the solvent phases.

- For solvents with small water concentrations, the brine can avoid the dehydration of the solvent, and upflow operation is preferred.

In spite of its lower dehydration capacity compared with caustic desiccants, calcium chloride is often preferred for big dehydration processes, such as natural gas dehydration. The use of caustic desiccants involves a specific treatment of liquid effluents. That is why caustic desiccants are interesting when very low contents of residual water are needed. Another case where caustic desiccants are preferred is when an acid effluent is present on the plant, in order to neutralise it before treatment.

\section{2 "SMALL" PILOT EXPERIMENTS}

\subsection{Experimental Set-up}

The experimental set-up is a column $150 \mathrm{~mm}$ in diameter, with a maximum bed height of $400 \mathrm{~mm}$ of solid desiccant.
The column is operated in upward flow mode, and is fed by a hydrocarbon flow rate from 50 and $250 \mathrm{~L} / \mathrm{h}$. The flow rate is chosen to simulate typical flow velocity on industrial columns. The column is filled with a height of solid desiccant of $200 \mathrm{~mm}$, and then is fed with a specific flow rate. The superficial velocity in the column, calculated as inside an empty column, varies between 0.7 and $3 \mathrm{~mm} / \mathrm{s}$. For each set of flow conditions, once the flow conditions are stabilised, the water concentration in the solvent is measured both at the inlet and outlet of the column. It was checked that the experiment's time duration was short enough to avoid any significant evolution of the outlet concentration between the beginning and the end of an experiment. Experiments are also short enough to neglect the solid consumption and any modification of the specific exchange area.

Tests are performed with $14 \mathrm{~g}$ "cushion" moulded pieces of calcium chloride and with caustic potash and soda of two sizes: $9 \mathrm{~g}$ and $28 \mathrm{~g}$ pieces. The two kinds of moulded pieces have exactly the same shape but different sizes. Equivalent hydraulic diameters of these moulded pieces are 2.3, 2.0 and $3.0 \mathrm{~cm}$, respectively.

\subsection{Mass Transfer Correlation for Caustic Desiccants}

When the dehydration is only limited by the mass transfer, as is expected in this case, the steady-state concentration of water $C$ at the distance $x$ from the inlet of the column follows the expression (mass balance):

$$
\frac{\partial C}{\partial x}+\frac{K A S}{Q} C-\frac{L}{P e} \frac{\partial^{2} C}{\partial x^{2}}=0
$$

$K$ is the liquid/solid mass transfer coefficient, $A$ is the solid specific area, $S$ is the column cross-section area and $Q$ is the solvent flow rate. $L$ is the column length, and $P e$ is the 
Peclet number depending on the axial dispersion inside the column $\left(P e=U_{s} L / D_{a x}\right)$.

TABLE 1

Solvent properties

\begin{tabular}{|c|c|c|c|}
\hline & DPG & Toluene & \\
\hline$D$ & $2.30 \mathrm{E}-09$ & $6.40 \mathrm{E}-09$ & $\mathrm{~m}^{2} / \mathrm{s}$ \\
\hline$\mu$ & 0.0014 & 0.00059 & Pa.s \\
\hline$\rho$ & 1000 & 867 & $\mathrm{~kg} / \mathrm{m}^{3}$ \\
\hline
\end{tabular}

As a first step, the assumption of plug flow is done, even if the ratio $d_{c} / d_{p}$ is small $(<20)$. At such a low $d_{c} / d_{p}$ ratio, it is known that some channelling effects can appear near the walls. This point is validated later in the paper. Under perfect plug flow conditions, $P e=\infty$ and Equation 1 are integrated in order to calculate water concentrations at the column outlet:

$$
C_{S}=C_{0} \cdot \exp ^{\left(-\frac{L K A S}{Q}\right)}
$$

The mass transfer is supposed to be only limited by the diffusion of water in the thin film around the particles. It is then considered as an external mass transfer, and its coefficient depends on both the properties of the solvent and hydrodynamics in the column. The link between these phenomena is classically written in the non-dimensional form as a Sherwood number depending on the Reynolds and Schmidt numbers. Generally, the correlation form between these numbers is

$$
S h=\frac{K d P}{D}=a+b \operatorname{Re}^{c} S c^{d}
$$

where $d_{p}$ is the particle equivalent diameter and $D$ the water molecular diffusion coefficient of water in the solvent phase.

For example, for spheres, the correlation of Ranz \& Levenspiel [6] gives: $a=2$ (this term is negligible in flow conditions), $b=1.8, c=0.5, d=0.333$.

The solvent properties are given in Table 1 .

Molecular diffusivities are estimated using the Wilke \& Chang correlation [7]. A correlation for the Sherwood number has been developed to match the experimental data obtained with caustic desiccants and with both tested liquid phases. Specific areas of each moulded piece size are well known by the manufacturers: $115 \mathrm{~m}^{2} / \mathrm{m}^{3}$ for $28 \mathrm{~g}$ pieces, $170 \mathrm{~m}^{2} / \mathrm{m}^{3}$ for $9 \mathrm{~g}$ pieces. The optimal expression for the Sherwood number is the following:

$$
S h=\alpha \cdot R e^{\beta} \cdot S c^{0.333}
$$

where $\alpha$ is a constant between 1 and 3 and $\beta$ is a constant between 0.4 and 0.6 (not published for confidential reasons). This result is significant of an external mass transfer limitation since $R e$ and $S c$ exponents are typically those of liquid/solid mass transfer expressions. Figure 6 presents the comparison between experimental data and results obtained

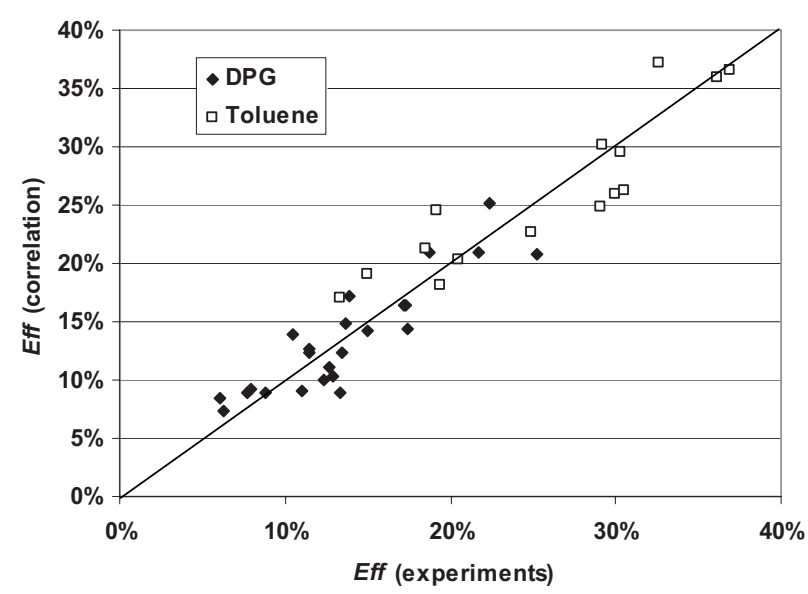

Figure 6

Model/experiment comparison of the dehydration efficiency of solvents by caustic desiccants.

using correlation (4) in terms of dehydration efficiency. The dehydration efficiency, Eff, is defined as:

$$
E f f=\left(C_{0}-C_{S}\right) / C_{0}
$$

The mean prediction error of the correlation (4) is $14 \%$. The assumption concerning the plug flow is validated by comparing solutions from Equation 1 for different values of the Peclet number. For the following typical conditions: $L=0.2 \mathrm{~m}, U_{s}=3 \mathrm{~mm} / \mathrm{s}, K=4 \times 10^{-4} \mathrm{~m} / \mathrm{s}, A=115 \mathrm{~m}^{-1}$, Figure 7 reports simulation results for $P e=14,40,80$, $\infty$. The relative difference in water concentration between the cases $P e=14$ and $P e=\infty$ is only $5 \%$ at the column outlet. This shows that axial dispersion can be neglected when cushion moulded pieces are used.

\subsection{Mass Transfer Correlation for Calcium Chloride Desiccant}

The same kind of analysis was performed with $14 \mathrm{~g}$ moulded pieces of calcium chloride $\left(A=145 \mathrm{~m}^{2} / \mathrm{m}^{3}\right)$ and for the same range of flow rates. Experiments were also done with spherical pearls of calcium chloride $1.6 \mathrm{~mm}$ in diameter. This last experiment was done to observe the influence of the diffusion velocity inside the calcium chloride. A single external mass transfer limitation is not sufficient to explain and reproduce experimental results, and a diffusional limitation inside the salt is guessed. This diffusional limitation is represented as an additional contribution, $k_{d}$, to the global mass transfer limitation used in Equation 2:

$$
\frac{1}{K}=\frac{1}{k_{L} A}+\frac{1}{k_{d}}
$$

where $k_{L}$ is calculated by Equation 4 , and $k_{d}$ is expressed as an empirical function of the solid particle diameter:

$$
k_{d}=\chi \cdot d_{p}^{\gamma}
$$




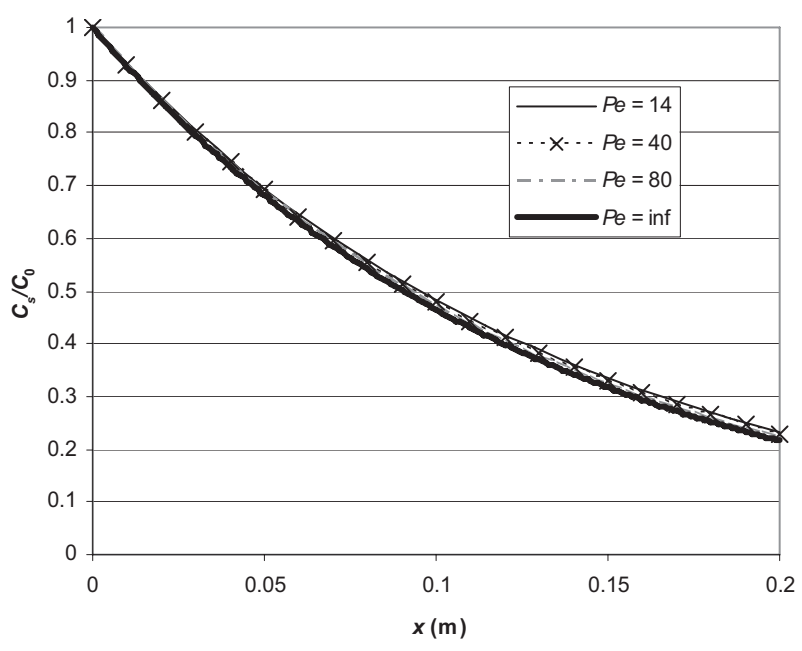

Figure 7

Effect of the axial dispersion (Peclet number) on the dehydration efficiency.

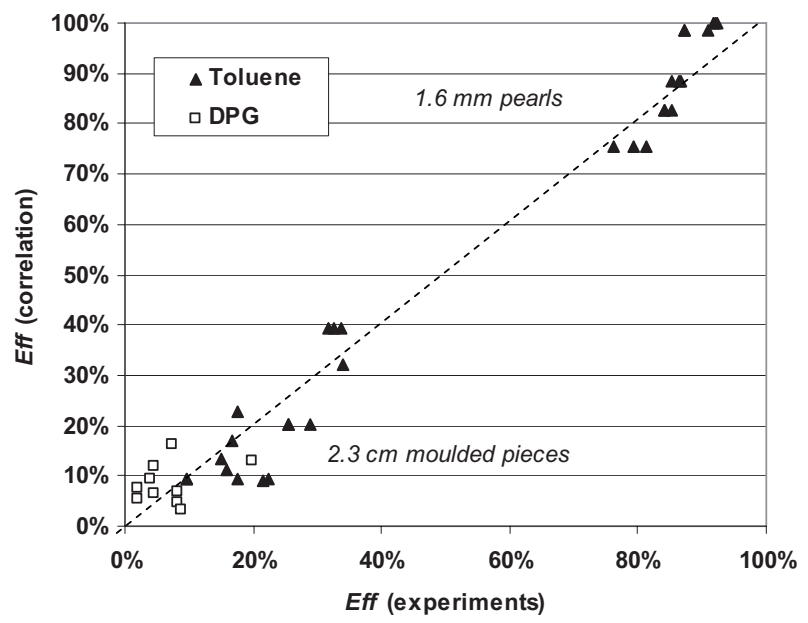

Figure 8

Model/experiment comparison of the dehydration efficiency of solvents by calcium chloride.

A comparison between experimental dehydration efficiencies and those calculated by the model using Equations 2, $4,6,7$ with $\chi=1.55 \times 10^{-5}$ and $\gamma=-0.77$ is reported in Figure 8. The model predicts experimental results with a relative dispersion (mean error $\approx 20 \%$ ), especially concerning experiments done with the moulded pieces. The model reproduces the effect of the solid particle hydraulic diameters: this validates assumptions concerning the effect of internal diffusion on global mass transfer.

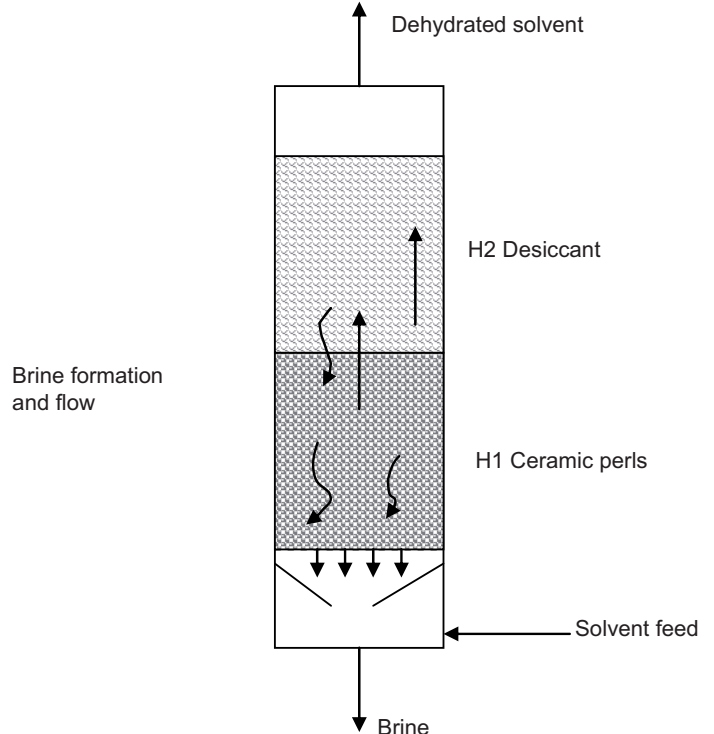

Figure 9

Desiccant column with inert pearls.

\subsection{Effect of Inert Beads Upstream of the Desiccant Fixed Bed}

It was observed during the experiments with DPG that a significant amount of brine is created during dehydration. It has been shown that the brine could take part in the dehydration, especially if the brine is in contact with a very humid solvent. For this reason, it can be useful to add, in upward flow conditions, a bed of inert beads (such as ceramic, for instance) upstream of the desiccant bed to enhance liquid/liquid contact efficiency in the counter-current flow of solvent and brine. The scheme of bed loading is described in Figure 9.

This mode of operation was tested on the small pilot by introducing a bed of $140 \mathrm{~mm}$ of ceramic beads $18 \mathrm{~mm}$ in diameter. Above this inert bed, the active bed of solid desiccant is loaded, with the same height. Experiments are performed with $9 \mathrm{~g}$ soda and potash moulded pieces. Only the DPG is tested as the hydrocarbon phase. Results are interpreted by calculating the global mass transfer coefficient, $K A$, from Equation 2:

$$
K A=-\frac{Q}{S L} \ln \left(\frac{C_{S}}{C_{0}}\right)
$$

The measured values of $K A$ with and without the inert bed are reported in Figure 10 for different values of the liquid flow rate and for the same total bed height. The results shown are normalised by $K . A_{0}$, the maximum value of $K . A$ obtained for each solid (potash or soda).

Results obtained with or without inert beads are fairly scattered, but follow the same trend versus the liquid flow 


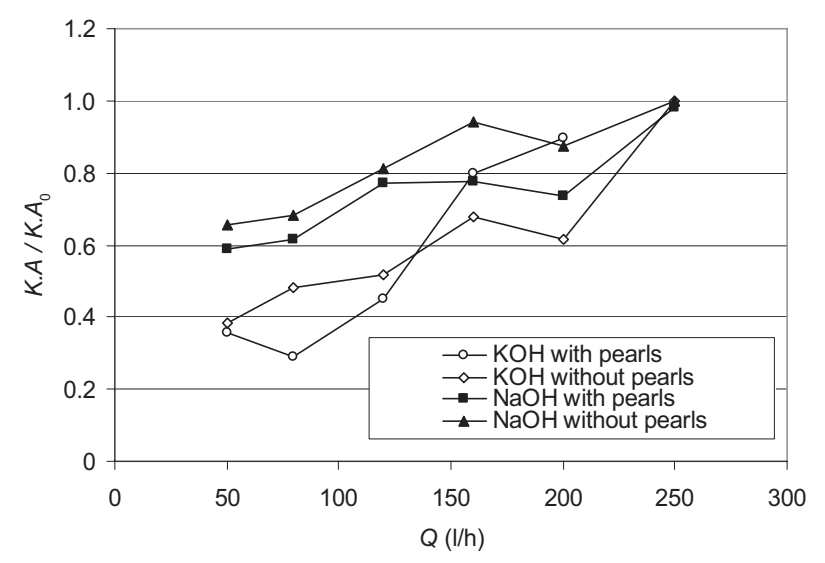

Figure 10

Global mass transfer coefficient, KA, over a whole bed with or without inert ceramic pearls.

rate. This signifies that the height of ceramic beads has roughly the same dehydration efficiency as the desiccant bed. The brine can greatly participate in the dehydration, and the optimisation of the interfacial area between the brine and the solvent can lead to significant cost reductions in terms of desiccant consumption.

\section{DESIGN OF INDUSTRIAL COLUMNS}

The design of industrial columns requires a good knowledge of dehydration kinetics, but it also requires being able to predict the time evolution of the performances of a drying column. A critical parameter of the design is the dehydration efficiency at the end of a run. For this reason, a very simple model is used in order to couple the mass transfer mechanism to the loss of solid height inside the column induced by the desiccant consumption. In a second step, the model is compared with some long-run experiments done inside a semi-industrial column.

\subsection{Solid Consumption}

A simple model was developed in order to predict the evolution of dehydration performances with solid consumption over time. Different assumptions were made: the brine is saturated in water at the outlet of the column, and the flow rate of the liquid is constant between the inlet and outlet of the column. The bed porosity, $\varepsilon$, and the specific area of desiccants, $A$, are constant during the run. This last assumption is based on experiments done with new and partially consumed moulded pieces. For these experiments, calculated mass transfer coefficients were found to be close. This result shows that if the specific area and the porosity evolve during the bed consumption, their effects are antagonistic to

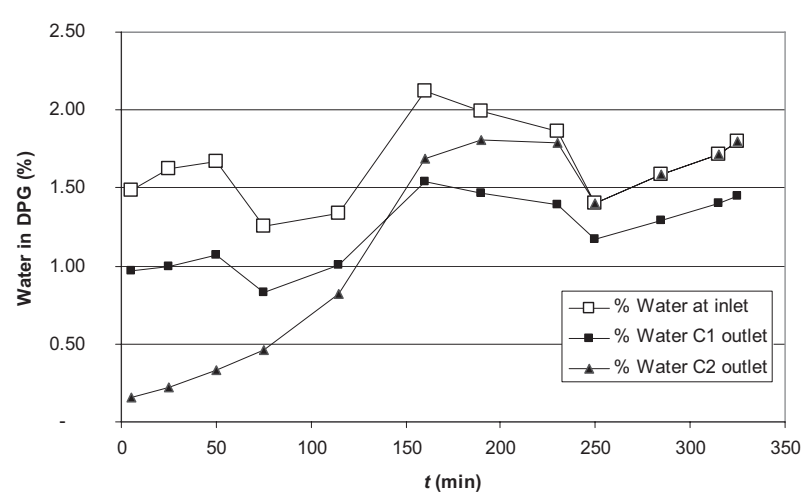

Figure 11

Water concentrations at inlet and outlet of columns C1 \& C2.

mass transfer and the resulting mass transfer coefficient can be considered as constant.

The following equations are solved:

Instantaneous water concentration at the outlet of the column:

$$
C_{S}(t)=C_{0}(t) \exp ^{\frac{-L(\mathrm{t}) K A S}{Q}}
$$

The bed height, $L$, can be expressed as a function of the mass of solid by

$$
L(t)=M(t) /\left(S \cdot(1-\varepsilon) \cdot \rho_{D}\right)
$$

where $M(t)$ is the mass of desiccant and $\rho_{D}$ is the desiccant density.

The mass of solid in the column at $t=0$.

$$
M_{0}=S \cdot Z_{0} \cdot(1-\varepsilon) \cdot \rho_{D}
$$

The mass flow rates of water and brine, $m_{\mathrm{H}_{2} \mathrm{O}}$ and $m_{b}$ (in $\mathrm{kg} / \mathrm{s}$ ), collected at the bottom of the column can be expressed as:

$$
\begin{gathered}
m_{\mathrm{H}_{2} \mathrm{O}}=Q\left(C_{0}-C_{S}\right) \cdot \rho_{L} \\
m_{b}=Q_{\mathrm{H}_{2} \mathrm{O}} / X
\end{gathered}
$$

where $\rho_{L}$ is the solvent density, $X$ is the mass fraction of water in the brine at equilibrium $(0.9 \mathrm{~kg}$ of water per $\mathrm{kg}$ of potash in the brine).

And the mass balance on the solid in the column:

$$
\frac{\partial M}{\partial t}=-m_{b}
$$

\subsection{Validation on "Large" Pilot Experiments}

The model was compared with experimental data acquired on two parallel columns in PMMA, $300 \mathrm{~mm}$ in diameter and $800 \mathrm{~mm}$ high. Each column is fed by a flow rate of DPG fixed at $900 \mathrm{l} / \mathrm{h}$. The columns are filled with $9 \mathrm{~g}$ moulded pieces of potash (column $\mathrm{C} 1$ ) and potash flakes (column C2). Both columns have the same inlet feed. The experimental set-up does not have a sufficient tank to prepare the 

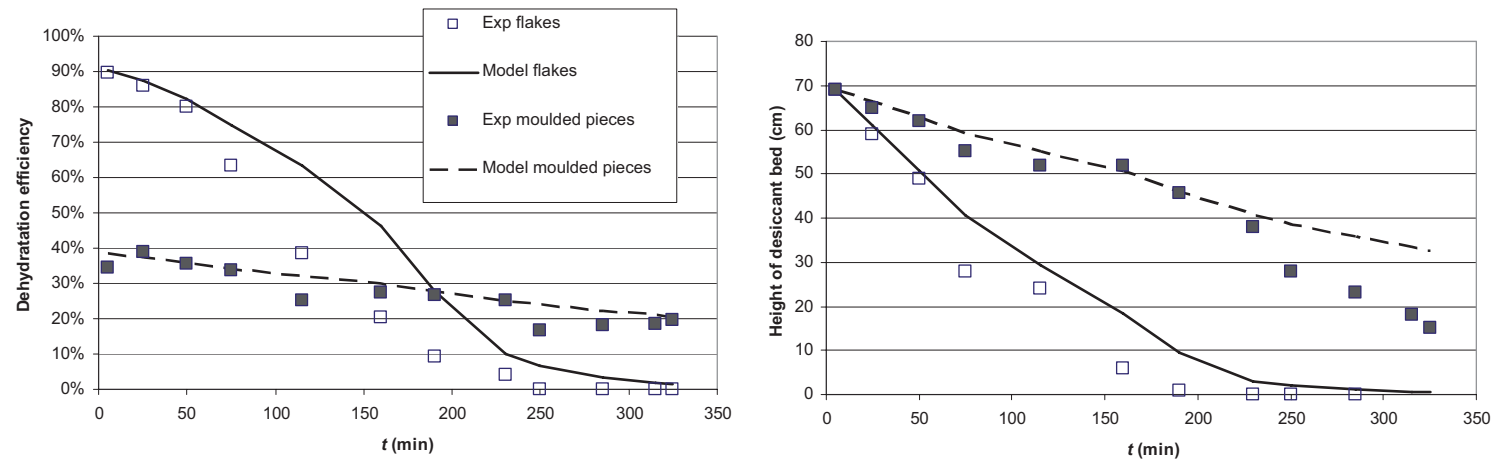

Figure 12

Dehydration efficiency and height of solid time evolution: experiments and simulations for flakes and moulded pieces (solvent: DPG, desiccant: KOH $9 \mathrm{~g}$ moulded pieces).

DPG solution for the whole test, so the solution to feed the pilot is prepared during the test. This induces fluctuations in the solution composition at the inlet of the columns, around the mean value of $1.5 \%$ of water. These fluctuations have to be taken into account for any result analysis. Figure 11 presents the water concentrations at the inlet and outlet of the columns versus time.

The liquid/solid mass transfer coefficient of the potash moulded pieces is calculated from correlation (4). In the case of the flakes, the mass transfer is not well known, nor their specific area, so the global term, $K A$, is directly measured on the small pilot, at the same velocity. This measurement gives $K A_{\text {flakes }}=0.012 \mathrm{~s}^{-1}$. Comparison between experimental and simulated column heights and dehydration efficiencies is reported in Figure 12.

In spite of the significant fluctuations in the water concentration at the inlet and the outlet of the columns, experimental dehydration efficiencies are very little scattered and follow coherent trends. The evolution of the efficiency and the height of moulded pieces is well predicted by the model, when the height is larger than $30 \mathrm{~cm}$. For lower bed heights, the model underestimates the bed consumption rate. This is probably due to an increase in the mass transfer term, KA. Such a phenomenon has not been seen in the small pilot, but inside this column, the diameter is probably large enough to allow a better reorganisation of the moulded pieces during solid consumption and thus an increase in the mass transfer.

Concerning experiments done with the desiccant flakes, the height of the solid is roughly well predicted by the model but the efficiency of dehydration is overestimated. A quick degeneracy of the plug flow in the bed due to the formation of chimneys or preferential paths is suspected, as can be observed in Figure 2. Chimneys allow a part of the fluid to bypass the desiccant, so it is logical to see a loss of efficiency in dehydration by this phenomenon.

\section{CONCLUSIONS}

Dehydration operations with solid desiccant can follow very different behaviours depending on the solvent to be treated or its water concentration, and also depending on the characteristics of the desiccant: material and shape. It was observed during this study that dehydration with caustic desiccant is limited by external mass transfer, and this phenomenon was successfully characterised through a correlation between Sherwood, Reynolds and Schmidt numbers. This result is important for the design of industrial columns. Dehydration kinetics observed with calcium chloride is different, and is not only limited by external mass transfer, but also by the internal diffusion of water inside the desiccant.

When caustic desiccants are used with a highly wetted solvent, dehydration generates formation of a brine phase, which can increase the dehydration efficiency at the bottom (inlet) of the column, especially if the liquid-liquid contact surface is optimised by the use of a bed of inert beads or other packing technology.

A very simple model was developed to estimate the evolution of the performances in columns over time and to predict bed ageing. The model is in good agreement with experimental results in the case of the use of moulded pieces. However, it is less accurate when applied to columns using desiccant under the flake formulation. This is supposed to be a consequence of a strong degradation of hydrodynamics due to the formation of liquid chimneys in the granular bed.

The comparison between ideal model prediction and experimental data exhibits the hydrodynamic issues encountered with particles of desiccants of small size, such as flakes, and the advantages in using moulded pieces to avoid them. This is no longer true if the loss of efficiency due to the use of bigger solid pieces is crippling. 


\section{REFERENCES}

1 Ausikaitis J.P. (1979) Drying agents, in Kirk Othmer Encyclopedy of chemical technology, 5th edition, Wiley interscience, pp. 115-130.

2 Bower J.W. (1934) Comparative efficiency of various dehydrating agents used for drying gases (a survey of commercial drying agents), Bureau of Standards J. Res. 12, 241-248.

3 Barnett J.W. (1996) New salt products dries distillate streams, eliminates haze, Oil Gas J. 15, 68-70.

4 De Hemptinne J.C., Dhima A., Zou H. (1998) The importance of water-hydrocarbon phase equilibria during reservoir production and drilling operations, Revue de l'Institut Français du Pétrole 53, 3, 283-301.

5 Ruthven D.M. (1984) Principles of Adsorption and Adsorption Processes, Wiley \& sons, New York.

6 Kunii D., Levenspiel O. (1969) Fluidization engineering, Wiley \& Sons, New York.

7 Wilke C.R., Chang P. (1955) Correlation of diffusion coefficients in dilute solutions, AIChE J. 1, 264-270.

Final manuscript received in February 2008

Published online in August 2008 